tion is given. The payments consist of an entrance-fee of 5 fl., and a payment of 50 fl. per annum ; and in addition $6 \mathrm{fl}$, is charged for every day's work of 7 hours in the chemical laboratory; rofl. for 2 afternoons of 3 hours in the physical laboratory.

In addition to the subjects required in each special department, lectures or instruction are given in the following subjects, and attendance at some of them is strongly recommended to all students, in order to give a wider culture than would be attained by exclusive attention to his special pursuit:-(I) Exercises in Literature and History; (2) the French and English Languages; (3) the General History of Art ; (4) National Economy ; (5) Commercial Knowledge; (6) the Principles of Jurisprudence; (7) Physical Geography; (8) Zoology; (9) Systematic Botany; (Io) Singing and Gymnastics.

The course in the Lower School extends overtwo years, in which the following subjects are compulsory :-First year. (I) History and Literature with the German Languages; (2) Higher Algebra ; (3) Stereometry and Trigonometry; (4) French ; (5) Outline Geometry; (6) Free-hand Drawing. Second year. (I) History and Literature with the German Language ; (2) Analytical Plane Geometry; (3) Algebraic Analysis, the Differential and Integral Calculus; (4) Higher Algebra; (5) Experimental Physics; (6) Mechanics; (7) French; (8) Free-hand Drawing ; (9) Outline Geometry.

In the-special schools for Architecture, Engineering, Mechanics, Technical Chemistry, and Agriculture, the entire course extends over a period of from two to four years. The extent to which the studies are carried will be illustrated by the following abstracts of the curriculum in the Agricultural School, the shortest of the courses:First year (I) Experimental Physics; (2) Experimental Chemistry ; (3) Chemical Exercises ; (4) Histology and Morphology ; (5) Vegetable Physiology; (6) Systematic Botany (with excursions) ; (7) Zoology ; (8) Mineralogy ; (9) The Study of Rocks; (IO) Anatomy of Domestic Mammalia; (II) Physiology of Domestic Mammalia; (12) External form of Domestic Mammalia ; (I3) Agricultural Implements and Machines ; (I4) National Economy; (15) Mathematics; (16) The Drawing of Plans. Second year-(I) Chemical Exercises ; (2) Agricultural Chemistry ; (3) Practical Microscopy; (4) Practical Physiology ; (5) The Diseases of Plants; (6) General Agriculture; (7) Special Agriculture; (8) General Breeding of Animals; (9) Special Breeding of Animals; (ro) The Commerce of Agriculture ; (II) The Cultivation of Garden, Orchard, and Vine ; (12) Internal Diseases of Domestic Mammalia; (13) External Diseases of Domestic Mammalia; (14) Technology (Heating and Lighting); (15) Agricultural Book-keeping ; (I6) Irrigation, Tilling, \&c. ; (I7) History and Literature of Agriculture ; (18) Practical Geometry.

To assist in the studies of the pupils there are chemical and physical laboratories, an experimental farm, mineralogical, zoological, and botanical collections, models of machinery, designs, libraries, excursions into the country, \&c. Under special circumstances students can be admitted as "Hospitanten" to certain only of the studies, without going through the entire course ; but care is taken that this does not interfere with the regular studies of the other students.

\section{LAKE VILLAGES IN SWITZERLAND}

$\mathrm{T}$ is satisfactory to find that the correspondents of some of the daily journals are now in the habit of giving scientific information to their readers. The following is taken from the Standard:-

"An interesting archæological discovery has recently been made on the shores of the Lake of Bienne. The Swiss Government has been for a long time endeavouring to drain a considerable tract of land between the two lakes of Morat and Bienne, but in order to do this effectually it has been found necessary to lower the level of the latter by cutting a canal from it to the lake of Neuchatel. At the beginning of the present year the sluices were opened, and the waters of the Lake of Bienne allowed to flow into that of Neuchatel. Up to the present time the level of the Bieler See has fallen upwards of three feet, and this fall has brought to light a number of stakes driven firmly into the bed of the lake. This fact becoming known, a number of Swiss archæologists visited the spot, and it was decided to remove the soil round these stakes to see whether any remains of a Lacustrine village, which they suspected had been raised upon them, could be traced. At a distance of between five and six feet from the present bed of the lake the workmen came upon a large number of objects of various kinds, which have been collected and are at present under the custody of $\mathrm{Dr}$. Gross, of Locrass. Among them are pieces of cord made from hemp, vases, stags' horns, stone hatchets, and utensils used apparently for cooking. The most precious specimen is, however, a hatchet made of néphrite (the name given to a peculiarly hard kind of stone from which tha Lacustrines formed their cutting instruments). This hatchet is sixteen centimetres long by seven broad, and is by far the largest yet discovered in any part of Switzerland, no other collection having any measuring more than eight centimetres in length. A quantity of the bones found at the same time have been sent to Dr. Uhlmann, of München. buchsee, for examination by him, and he finds that they belong to the following animals, viz. :- stag, horse, ox wild boar, pig, goat, beaver, dog, mouse, \&c., together with a number of human bones. If the level of the lake continues to sink, it is hoped that further discoveries will be made, and the scientific world here is waiting the result of the engineering operations with keen interest."

\section{NOTES}

Wr have great pleasure in announcing that Prof. Andrew C. Kamsay, F.R.S., has been appointed Director-General of the Geological Survey in the room of the late Sir Roderick I. Murchison.

AT the moment of going to press we have received the announcement of the death of Prof. Goldstiicker, the eminent Sanscrit scholar. He died on Wednesday morning.

Mr. G. B. Alrv, the Astronomer Royal, and Prof. Agassiz, were elected foreign associates of the Académie des Sciences at Paris in the room of the late Sir J. Herschel and Sir R. I. Murchison at the meeting on the 26 th ult.

Dr. Maxwell Simpson, F.R.S., has been elected as successor to the late Dr. Blyth in the chair ;of Chemistry, Queen's College, Cork. Dr. Simpson is well known to men of science at home and abroad as an accomplished chemist, and one who has been especially distinguished for his original researches.

THE Crystal Palace Company's School of Art, Science, and Literature is about to take an important step, having for its object the emphasising of the science branch of the school, in order that eventually the south of London may be provided with an institution which, in a measure, may represent the Royal and London Institutions which already exist in the west and centre. The step consists in adding to the courses of lectures on scientific subjects already given special courses to be given from time to time by scientific men of eminence, similar to the courses given in the Institutions before referred to; and it is hoped that the same lectures and the same standard of excellence and illustration. may be secured. As the lecture theatre of the school has been burnt down, the lectures, pending its rebuilding, are to be given in the theatre in the Crystal Palace; but it need scarcely be stated that these lectures have no connection with the Crystal Palace, except so far as the School of Art, Science, and Literature is connected with it, and that they will be given at a time when the 